\title{
LA EXPERIENCIA DE LA POBREZA Y SU IMPACTO EN LA ORGANIZACION POPULAR DE LA CIUDAD DE LIMA
}

\author{
María Angeles López Jiménez*
}

Lima es la metrópoli peruana que ha atraído hacia sí las poblaciones emigrantes de las otras provincias del país. El encuentro entre limeños y provincianos ha supuesto retos inmensos de aculturaciones múltiples, en un proceso histórico de lucha por el espacio y por los recursos urbanos cada vez más escasos. Lima es una ciudad colapsada, en la que parece "agotada su capacidad de reproducirse como ciudad y como mercado" (Olivera 94). Lima es un paradigma de los desafíos a los que se enfrenta la metrópoli urbana en cuyos intersticios, las relaciones entre la sociedad civil, la sociedad política y la sociedad comunitaria (1) han extremado las tensiones derivadas del empobrecimiento de los modos de vida de sus habitantes.

La crítica a la gestión política que ha causado tal colapso no impide, mas bien favorece, la existencia de todo un sustrato de redes informales de trabajo y de organización popular, que se enfrenta hoy a un reto importante: el de evolucionar exitosamente de la autogestión comunitaria a la participación ciudadana en las instituciones políticas de la democracia formal.

Aquí se exploran algunas de las claves de dicho tránsito, partiendo de la vivencia de los propios actores sociales: los sectores populares, sus organizaciones, las organizaciones no gubernamentales laicas y religiosas, los representantes del gobierno local y los interlocutores del gobierno nacional (2). (1987a)

(*) Profesora titular en la Universidad de Zaragoza

(1) Una buena acotación de los tres ámbitos es la que propone Salvador Giner

(2) La exploración de estas claves es parte de un proyecto de investigación más amplio que se llevó a cabo bajo mi dirección entre 1991 y 1993. Fue subvencionado por el Plan Nacional de Ciencia y Tecnología (CICYT) y abordó el estudio de la "Participación ciudadana y las organizaciones populares en Santiago de Chile y Lima." El trabajo de campo sobre el que reposa este análisis se ha basado en la aplicación de una metodología de carácter cualitativo, con utilización de las siguientes técnicas de investigación: observación participante, entrevistas individuales y grupos de discusión. Los sectores populares que aquí se exploran viven en cuatro tipos de hábitat urbano diferenciados económica, social, cultural y espacialmente. Los tipos de hábitat seleccionados para el estudio son los siguientes: 1) Una parte del casco antiguo de la ciudad, caracterizada por encontrarse en un proceso de deterioro: Barrios Altos. 2) Un sector poblacional con gran tradición organizativa y reivindicativa: la zona baja del Agustino. 3) Un sector popular de reciente creación o surgimiento situado en la periferia de la ciudad: los pueblos jovenes de los cerros de Chorrillos. 4) Un sector popular en ascenso social, con presencia de profesionales jóvenes: la urbanización San Juan de Miraflores.
Una primera clave de la vida en la ciudad, que la atraviesa y afecta es la experiencia de la pobreza.

Los datos oficiales que maneja el gobierno de Fujimori en diciembre de 1992, reconocían que 15 millones de peruanos son pobres y cuatro millones y medio viven en situación de extrema pobreza (3). La situación no sólo es dramática por su cantidad, sino también por su progresividad. Hasta 1981, había 4 millones de pobres. Su aumento es galopante, a medida que se endurecen las políticas de ajuste económico.

Secuelas visibles de la pobreza que atraviesa la metrópoli de Lima son la precariedad o falta de infraestructuras y equipamientos urbanos de gran parte de las urbanizaciones en las que viven los sectores populares, la escasez de la vivienda, del agua, de la electricidad, el deterioro o falta de empleo y la consiguiente extensión de la informalidad laboral, las dificultades de alimentación básica, la fragilidad de la salud, la quiebra de la esperanza de vida, no sólo en términos biológicos sino de expectativas sociales.

¿Cómo perciben los sectores populares de los cuatro distritos estudiados en Lima esta situación de crisis?. ¿Qué estrategias de supervivencia generan y como se reconstruye a través de ellas la propia identidad social? ¿Cómo se afirman las identidades de género y generación, de nación y etnia a través de las orientaciones de comportamiento individual y colectivo? ¿Cómo se complementan las dimensiones de la identidad social y de la cultura política para connotar y conformar las orientaciones y estrategias del comportamiento, y su carácter individual o colectivo? ¿Qué significado adquiere el presente y el futuro?.

\section{LA EXPERIENCIA DE LA POBREZA. SU IMPACTO EN LA IDENTIDAD DE HOMBRES Y MUJERES JÓVENES.}

Los sectores populares viven la condición de pobreza con pesimismo, conscientes del tremendo desafío que supone superarla cuando sus recursos son tan limitados, tan es-

(3) Datos facilitados por la Asesoría del Ministerio de la Presidencia. 
casa la atención que el Estado les presta y tan evidente el vacío legal que les priva de instrumentos de protección y defensa. Las reacciones más contrapuestas son las que separan a los jóvenes varones, jefes de familia y desempleados o de empleos precarios y a las mujeres de su misma condición social y habitacional. La situación más paradigmática de las estudiadas es la que afrontan las jóvenes familias de El Agustino.

Los jóvenes varones reaccionan con comportamientos desalentados y en sus propias declaraciones se resumen las grietas internas producidas por la espiral de la pobreza, vivida en tensión familiar, laboral y social: "No hay trabajo... y cuando lo hay se gana cada vez menos, las empresas sólo velan por sí mismas y rebajan los sueldos, se están haciendo ricas con Fujimori, no hay vivienda, no tenemos documentos ni dinero para sacarlos, no hay apoyo de nadie, las autoridades se olvidan de que estamos acá, el gobierno nos sigue martirizando, somos ignorantes, los muchachos abandonan, la mujer se quiere ir porque piensa que uno gana más de lo que tiene para darle, ... no hay ayuda para los hombres, sólo para las mujeres, ahorita acá en el Perú cuanta gente pobre que no puede mantener sus hogares se tiene que meter a las malas costumbres, a robar, cuantas mujeres se meten a la prostitución, cuantos hombres caen en una batida por falta de documentos y ahí los agarran a palos y los patean, los empapelan y ¿donde termina esa persona? en la cárcel y ¿cuando sale?, supongamos que no tiene documentos, tiene que pagar, muchas personas van a la cárcel porque no pueden pagar a los policías... sales de la cárcel, si no pagas te quedan antecedentes y cuando uno quiere buscar trabajo lo rechazan, abusan de nosotros porque somos pobres, somos gente con problemas... yo estoy desesperado" (4). (Grupo de varones jóvenes de El Agustino)

Los jóvenes varones de barrios marginales se encuentran ante un dilema, y una amenaza. El dilema está entre optar por un trabajo precario con un sueldo escaso o por la apropiación ilegítima de los bienes ajenos. Si eligen el primero, disminuye su autoestima con la pérdida de autoridad familiar y de credibilidad ante la pareja. Si escogen el segundo, se internan rápidamente en un circuito de violencia marcado por la práctica de actividades delictivas, reconocidas como tales, aunque no deseadas, y por la vigilancia de los aparatos represores del estado, temibles por el hecho de serlo y porque además ejercen su función con arbitrariedad e impunidad.

La amenaza es la no existencia como ciudadanos por carecer de los documentos acreditativos de tales. Y precisamente su invisibilidad civil les hace más vulnerablemente visibles ante los grupos y organizaciones que dominan el mundo subterráneo de la economía sumergida, de la corrupción institucional y de la delincuencia

Los jóvenes varones pobres son las principales víctimas tanto del ejercicio de la violencia común como de la política

(4) Alicia Grandón (1990: 34) explica cómo la caída de ingresos remunerados del padre de familia, en el período de 1977 a 1984, acaba en la mayoría de los hogares del Agustino con la figura del padre como proveedor exclusivo, como una acentuación del proceso que se registra en los sectores populares de la ciudad. y sufren la represión del estado (y de sus oponentes violentos) tanto por una causa como por la otra. Están bajo sospecha permanente de subversión de las normas sociales y de incumplimiento de los deberes familiares, carecen de ayuda para salir de la situación por parte del Estado y de los recursos administrados a las mujeres en reconocimiento de la identidad social de éstas. Sin documentos identificatorios (cartilla electoral y cartilla militar) carecen de los derechos de la ciudadanía Todo ello debilita su fe en sí mismos y afirma su sentimiento de impotencia y de discriminación negativa, vividas individualmente. Así se va imprimiendo en la memoria del varón la crisis de su identidad masculina.

Desde este punto de mira, la acción política y social ejercida por el gobierno, los partidos y las organizaciones sociales es una farsa, en la que los más ricos se aprovechan de los recursos de los pobres y los más listos engañan a los más indefensos. Como ellos pertenecen al segundo grupo no encuentran razón alguna para confiar en nadie, salvo en la Iglesia Católica, porque al menos brinda a los más jóvenes la oportunidad de comunicarse sus problemas en un "espacio" alejado de las responsabilidades familiares y laborales. Por su parte, ya derrotados, la salida más inmediata y asequible es la inmersión en la fiesta colectiva ahogando las penas en alcohol, la salida mediata, cada vez más lejana, es la emigración. Su argumento para desear salir es que los ricos y los políticos protegen a sus hijos llevándoselos al extranjero. Allí fuera habría por tanto esperanza de romper, individualmente, las servidumbres experimentadas. Queda ahí, no obstante, la expresión de su buena voluntad hacia los varones que vienen detrás.

Esta visión oscura de su presente y de su futuro es reconocida por los varones de clase media baja, que reaccionan con empatía solidaria. Los jóvenes de San Juan de Miraflores denuncian la dureza de la situación que sus coetáneos pobres viven y sus causas. "(Estos jóvenes) quieren trabajar pero no saben en qué, no tienen documentos y es una secuela, quizá por dejadez, falta de orientación, quizá porque su familia no los ha motivado a preocuparse por sí mismos... muchos jóvenes han tenido que delinquir para alimentar a sus hijos.. me gustaría que alguien venga y me diga que es una mentira lo que veo pero no, es verdad". (Grupo de varones estudiantes de San Juan de Miraflores)

Los jóvenes de clase media baja, como contraste tienen identidad social porque tienen documentos, estudian y esperan encontrar trabajo e integrarse socialmente en las funciones tradicionales de su género. Desde este punto de mira, perciben también las dificultades de sobrevivencia $\mathrm{y}$ de inserción laboral pero a consecuencia de la crisis de la ciudad, no de su condición personal, puesto que tienen apoyo familiar en el proceso legal de adquisición de la ciudadanía, ni de su dimensión masculina, puesto que se están cualificando para el empleo y tienen expectativas de incorporarse al mercado laboral con los recursos de su identidad varonil.

Tampoco otorgan legitimidad a la dictadura, ni a las instituciones políticas, y afirman no esperar nada de ellas, pero creen en su capacidad personal de crear su propio empleo, (son los potenciales micro-empresarios) y en la fuerza operante de la vertebración social a dos niveles: las institu- 
ciones de origen cultural indígena de ayuda mutua, cultivadoras de la confianza, la perseverancia y el respeto a la autoridad, y la organización social para contribuir a la integración de los demás, que es consecuencia de los valores solidarios transmitidos por la educación religiosa. No piensan salir del país sino explorarlo fuera de las difíciles fronteras de la ciudad bloqueada o sumergirse en los intersticios de la misma hasta crear alternativas que sustituyan a las falsas propuestas de destrucción terrorista y de corrupción social Hay aquí un salto cualitativo importante que va desde la desorientación del comportamiento producida por la anomia de los primeros hasta la conducta normativa producida por la asunción de una función integradora de los segundos, usando la terminología durkheimniana.

Las mujeres de El Agustino acusan también la desprotección del Estado, el hambre y la enfermedad, el abuso masculino en el hogar y la ausencia del padre de sus hijos, pero se reafirman en su condición femenina para hacer frente a la situación. No hay que olvidar que cuentan con el respeto de las instituciones sociales, que les otorga la representación simbólica de los valores culturales solidarios ganada a pulso con su comportamiento. El testimonio de todos los portavoces sociales entrevistados, salvo el de los hombres de El Agustino, así lo confirma.

La preocupación de las mujeres por la vida y salud de sus hijos aviva su búsqueda de alternativas a la sobrevivencia: complementan el trabajo doméstico, con el trabajo extradoméstico y contribuyen, como usuarias de los servicios del vaso de leche y del comedor en un primer paso, como responsables de las actividades alimentarias en un segundo, a la organización popular para combatir la pobreza.

Hay razones de peso para su esfuerzo.

En primer lugar, se saben las máximas e incluso las únicas responsables de la protección de los hijos. "A él (el padre), no le preocupa... si los niños no comen.... " (Grupo de mujeres de Barrios Altos). A mayor esfuerzo por atender a los hijos, mayor autoestima. La extremosidad de la atención prestigia su imagen y la respetabilidad social así adquirida, les compensa del agotamiento.

En segundo lugar, se reconocen víctimas de la violencia doméstica enmarcada en un escenario más amplio, que también atrapa a los victimadores, sumidos todos en la condición de debilidad del pobre. Los cónyuges o compañeros del hogar son castigados por la policía en la calle, por los empresarios en su trabajo, por los terroristas en sus vecindarios, por los políticos en el gobierno. Las mujeres conjuran la violencia, sumando a sus obligaciones tradicionales las que oprimen al hombre. El se encuentra incómodo en el espacio doméstico, por su dificultad de responder a las demandas que allí se le hacen, y cree de paso agotadas las alternativas de rebelión en el espacio público. La mujer entonces, le sustituye como contribuyente a la economía de la casa y explora los recursos que el espacio público puede guardar. Para lograrlo necesita de la orientación de otros No pasa por su mente la huida individual sino la organización colectiva. La organización tiene problemas pero se afrontan desde una postura también normativa.
Unos y otras creen en la existencia de una manipulación de los poderosos a través de la organización pero si los primeros califican esta perversión de mal de la organización, las segundas la derivan de la corrupción de sus líderes. Para los primeros la solución es no organizarse, para las segundas, lo es el recambio de los líderes corruptos. Ellas se ven a sí mismas como alternativa.

\section{LA CULTURA POPULAR Y LA ACCIÓN COLECTIVA.}

Una constante en Lima es la referencia a la cultura como fuente de inspiración de la acción colectiva. Y la referencia cultural va habitualmente acompañada de una reafirmación de doble carácter, nacional y étnico.

La nación es el ámbito de los sentimientos compartidos, de la memoria colectiva, del símbolo que arraiga al territorio, del lenguaje común. Pero en un contexto histórico multiétnico, multicultural, y multilingüístico (la mezcla de todas las sangres de Arguedas) de procesos migratorios densos y asentamientos convulsos de las poblaciones en las ciudades y metrópoli capitalina, el sentimiento nacional es un magma de emociones diversas.

Los habitantes de la ciudad, como los del país, tienen preocupaciones e intereses que incluyen una multiplicidad de lazos de solidaridad vinculantes a las comunidades de origen y a las etnias, en el caso de los emigrantes, a la vecindad, en el de los que comparten demandas y estrategias de defensa colectiva del techo, del agua, del alimento, de la salud y de las infraestructuras urbanas, a la reafirmación cultural del criollismo en el centro histórico de la ciudad, en fin, a la religión, al trabajo, al género, a la generación entre otras. Todo ello diversifica cualquier intento de identificación y esteriliza cualquier esfuerzo simplificador de la complejidad de identidades posibles.

No obstante, y a grandes rasgos, se perfila una doble afirmación nacional. Por un lado, añorante de la comunidad primaria, por el otro, comprometida con la defensa de la ciudadanía. Ambas afirmaciones afloran en la narrativa de la población y en las disposiciones de las organizaciones populares.

La primera se inspira en las sedimentaciones con las que la memoria colectiva ha idealizado la tradición indígena.

La segunda se construye con la decisión deliberada de movilizar a los ciudadanos para defender su derecho a participar en el gobierno de la sociedad civil a través de instituciones políticas formales.

\section{EL PODER MOTIVACIONAL DE LA COMUNIDAD PRIMARIA.}

Los rasgos identificatorios de la peruanidad se nutren en la primera del mito del hombre primitivo, imaginativo, esforzado trabajador del medio adverso y solidario distribuidor de los recursos obtenidos con el trabajo común, disciplinado y sumiso a la autoridad comunal de carácter patriarcal. 
La peruanidad se conforma actuando sobre el territorio propio, con imaginación, honestidad, espíritu de sacrificio, coraje, decisión, espíritu de superación, arraigo a la tierra, fe y vena utópica, cualidades todas ellas (y muchas más que podrían desgranarse a partir de éstas) que sirven de base y fermento a la solidaridad popular y a la organización colectiva.

Los testimonios recogidos en los sectores populares de los cuatro barrios analizados reflejan el poder motivacional de la tradición para generar estrategias de sobrevivencia, las que en este ámbito, son siempre colectivas, porque incluso cuando son individuales, se asientan en la esperanza de contar con el apoyo de la comunidad. Reflejan también las corrientes ideológicas que dominan el liderazgo social popular y el de las organizaciones de apoyo.

Estos son algunos de los testimonios de los sectores populares:

"Las estructuras sociales que modelan la vida del peruano son duras", pero hay resquicios a la creatividad personal, que puede florecer "con el desarrollo de los recursos que existen y que aun no han sido explorados... hay que volver a los lugares de origen (y contar) con la ayuda de las comunidades que lo poco que tienen lo comparten contigo" (Varones Estudiantes San Juan de Miraflores). " Acá la gente peruana es más viva, es que se las ingenia, es así... viene de los antepasados" (Mujeres Jóvenes Profesionales). "El serrano no tiene reparo en ponerse a trabajar de lo que sea". (Grupo de Mujeres de Barrios Altos).

El nosotros comunitario lo reafirman espontáneamente, mujeres impulsoras de un comedor autogestionario en Chorrillos. "Nosotros nos organizamos... en el paquetazo, cuando vino la crisis se hizo como una olla común ¿no?... nosotros como madres de familia tenemos que seguir, como mujer, madres organizadas, esta es la meta, participar, organizarse y adelante... la única forma de salir es solidarizarnos". Como complemento, puede apuntarse el compromiso de los informantes juveniles de San Juan de Miraflores, que colaboran en actividades parroquiales de protección a la infancia o participan en actividades deportivas o ayudan en los comedores autogestionarios.

Todas las organizaciones sociales alaban el espíritu solidario de la gente y con ello quieren decir de los pobres, pero la invocación al pueblo no significa lo mismo en las religiosas, aquí fundamentalmente en la Iglesia Católica (5) que en las seculares, en las que operan en el ámbito nacional o metropolitano que en las que se mueven en los barrios.

Las organizaciones nacionales o metropolitanas tienen una visión más unitaria del pueblo, las organizaciones barriales la tienen más fragmentaria.

El mito del pueblo aparece en la iglesia, y en ella también se deshace. Léanse algunos testimonios:

"nuestra gran masa indígena no ha entrado en la civilidiados.

(5) La Iglesia Católica es la Institución más respetada en todos los ámbitos estu- zación occidental y cristiana, tiene otra manera de pensar, otra cultura, otra filosofía... nuestros andinos no hacen como nosotros que ponemos categorías, distinciones, divisiones, ellos tienen un pensamiento global". (Presidente Conferencia Episcopal del Perú). "E1 8 de agosto del 90 si este país no hubiera tenido esta capacidad de organización imagínate, la gente hubiera muerto como ratas... es algo cultural que viene de la concepción y organización de la sierra y está muy en la médula de las personas... Incluso cuando hay una mordaza de prensa feroz y de radio... tu te enterabas de todo, no sé si es una reminiscencia de los chasquis, la gente se lo comunica todo, a nivel de barrio, de cuadra... no hay individualismo" Fe y Alegría.

Y ahora, la constatación parroquial de las fuerzas desintegradoras de la comunidad:

"La miseria la hemos tenido siempre pero hay cosas que son de esta época... la familia falla y después el mundo se ha venido abajo, claro si la primera célula sana (se malogra) se complica todo el cuerpo... aquí es gente muy influencia$\mathrm{da}$, no tienen mucha personalidad... es un pueblo que lentamente, lentamente, se está deshaciendo... hay desconfianza, ataques, problemas por cuestiones de dinero o por los partidos políticos. (Parroquia de Chorrillos). "Existe recelo entre los de clase alta y media alta con relación a nosotros... y casi todos ellos son blancos, mestizos, los criollos ¿no? esos son por ejemplo los que te dicen, no, es que el peruano es flojo, el peruano es irresponsable, es mentiroso y cuando están hablando así están hablando de nosotros, de las otras razas inferiores a ellos... si tu que no eres peruano le dijeras eso pues no te lo aceptaría.. no les parece bien que sus hijos en la catequesis estén con los de los pueblos jóvenes... sí hay bastante desprecio... La gente aquí es demasiado buena, por ahí bajan a buscar trabajo las señoras a ver si encuentran para lavar, los hombres a ver si arreglan el jardín, los ven muy por encima, quizás dentro de ellos hay un poco de resentimiento porque estos son los que dominan el país, pero se identifican con los que dominaron antes ¿no? y así como aquellos les rechazan y no quieren juntarse con ellos, éstos no están contra ellos... este problema de las razas y de las clases sociales eso es un problemón aquí para que llegue a existir un pueblo unido, identificados como peruanos". "La gente se lleva bien, se organiza.... pero somos un pueblo que también está acostumbrado al autoritarismo, habrá alguno que quiere opinar pero eligen a un dirigente (y quieren), que les resuelva sus problemas". (Parroquia San Genaro Chorrillos).

La riqueza asociativa de la comunidad primitiva es evocada por las organizaciones vecinales de carácter suprabarrial, con un deseo, el de que se invierta en la reconstrucción de la deteriorada ciudadanía. Véase como ejemplo la interpretación de la Coordinadora Vecinal del Cono Norte:

"sabemos que hay un montón de organizaciones pero si tu preguntas a la gente (parece que) no hay nada, se organizan para todo, no es un invento de nadie, es la gente misma... el gran problema es la heterogeneidad y la debilidad.. se necesita un nuevo tipo de organización que aglutine, ya no tiene que ser una organización tradicional, tiene que ser una organización representativa de todo el mundo". 
En las organizaciones barriales aparece clara la fisura entre los herederos de la comunidad primitiva y rural, la andina, y los atomizados habitantes de la ciudad: la comunidad y la sociedad de la tradición sociológica:

"La gente viene organizada, es una costumbre comunal andina. El limeño está observando como hacer algo que no requiere mucho sacrifico es más flojo que la gente del interior. Los líderes comunales provienen de fuera". (Dirigente Vecinal Chorrillos).

"la gente que viene de la sierra es más organizada... (en el pueblo joven) hacen sus colegios, sus parques, sus pistas... hay bastante solidaridad, lo que no ve usted en ciudad... en la época de los incas se trabajaba a nivel comunal". (Dirigente Vecinal Barrios Altos).

Recapitulando. La solidaridad popular ayuda a sobrevivir pero no oculta las divisiones y desigualdades, ni las hace desaparecer.

Tampoco produce cambios significativos en las condiciones de vida de la gente, que es consciente de que aquellos dependen de un giro importante en la acción del Estado. Para presionarle, necesitan fortalecerse a través de organismos capaces de defender el interés común ante el gobierno de la nación. Es decir, necesitan instituciones legitimadas socialmente.

De ahí que las instituciones políticas de la democracia representativa sean un referente importante en la cultura popular, aunque se hayan hecho acreedoras a la desconfianza general, por el engaño con el que han respondido a las expectativas de la población, precisamente en los momentos en los que gran parte de ella, transitaba desde el cumplimiento de sus viejas tradiciones comunitarias a la participación en las nuevas instituciones ciudadanas.

Los testimonios son tan unánimes como contundentes de la asociación popular entre deterioro de la calidad de vida nacional y malhacer de unas élites políticas (y económicas) insolidarias con sus conciudadanos e insensibles a sus carencias. No se pueden desgranar aquí los testimonios recogidos. Baste la escueta afirmación de que "El Perú actualmente es un caos, es una sociedad dirigida autoritariamente por unos gobernantes más interesados en enriquecerse que en el desarrollo del país". (Grupo de Mujeres de Barrios Altos).

El escepticismo, el pesimismo, la impotencia parecen haber traspasado los propios tuétanos de la sociedad peruana. Sin embargo una observación más atenta de los diagnósticos y de las propuestas de las instituciones de apoyo, de las estrategias de las organizaciones populares más consolidadas y de la capacidad de transformación de las políticas de desarrollo local allí donde los municipios abren sus puertas a la participación popular, permite desvelar la existencia de comportamientos cívicos orientados a la reconstrucción de la ciudadanía. El sustento ideológico de estos comportamientos se encuentra en las opciones políticas progresistas que están abandonando su reduccionismo democrático y la resistencia a comprometerse con un proyecto político de estado.
La defensa de la democracia popular en el nivel microsocial y la apelación religiosa a la solidaridad ancestral, sobre las que se tejen las redes primarias de interrelación comunitaria y de protección de los derechos humanos, siguen en pie. Ahora, sin embargo, se complementan con una voluntad clara de crear nuevas bases para la democracia representativa. Ninguna de las organizaciones suscribe el discurso basista en su forma extrema, aquel que veía a la población como la única fuente legítima de actuación política, suspicaz de las instituciones formales de la democracia representativa y del aparato formal del estado moderno (6).

Se ha experimentado la escasa influencia política de un movimiento asociativo prolijo en números pero modesto en sus objetivos y la dificultad de generar desde él, un movimiento reivindicativo de largo alcance, capaz de producir nuevas organizaciones de representación y mecanismos de negociación con el estado que sustituyan o renueven a los desprestigiados partidos políticos. Se reconoce así que una sociedad organizada masivamente sólo para labores de emergencia no puede acumular fuerzas para alcanzar protagonismo en la puesta en marcha de políticas formales, económicas y sociales. Hay que cambiar por tanto esta situación y de ahí parte la cultura política de los noventa.

\section{LA VOLUNTAD GENERAL DE LA CIUDADANÍA.}

La voluntad de reconstruir la democracia representativa emerge de la voluntad popular porque está aun fresca en la memoria colectiva una experiencia de participación reciente que se niega a languidecer.

Sólo hace 25 años que el velasquismo inició un esfuerzo democratizador de grandes sectores de la sociedad. Las organizaciones populares reivindicativas del hábitat y defensoras de los derechos ciudadanos, acumularon experiencia organizativa local y llegaron a crear, en la década de los ochenta, una Federación Departamental de Pueblos Jóvenes y Urbanizaciones populares de Lima. La preocupación de las organizaciones populares en los años ochenta estribaba en cómo constituirse en interlocutoras válidas para los gobiernos municipales, y mantener así el impulso a la participación dado por una política de izquierda, desarrollada desde algunos de los ayuntamientos del país, entre ellos y como eje fundamental, el de Lima. Más aún, "dirigentes que provenían de las organizaciones populares asumieron roles de alcaldes, regidores, gobernantes en el país. De una lucha reivindicativa ante el Estado... se pasa a la necesidad de levantar propuestas, de gestionar la ciudad, de mandar. Esta experiencia se trunca cuando la Izquierda Unida pierde las elecciones". (Coordinadora Metropolitana de Organizaciones Vecinales)

Tras el velasquismo, es la derecha la que ha gobernado la nación y ha recuperado estrategias populistas del lide-

(6) Lehmann hace un análisis del basismo en su reciente historia del pensamiento social latinoamericano (1990). 
razgo tradicional (7). Se pasa así de una dinámica de participación popular a una rutina clientelista de acceso al poder político, que practican no sólo los partidos políticos, sino también las organizaciones populares.

El clientelismo es un mecanismo perverso de acceso a los recursos, que pretende acortar o suprimir el carácter alienante de las organizaciones formales que los proveen, y que las poblaciones aceptan de manera fatalista. Pero es grande el cansancio popular acumulado en tal sometimiento y mayor la decepción sufrida cuando la corrupción institucional corroe a sus propias organizaciones. A pesar de ello, queda poco lugar para las recriminaciones. Las demandas de alimentación, salud, empleo, dan lugar como se ha dicho antes, a la aparición de nuevas organizaciones populares de sobrevivencia, que funcionan mejor con el apoyo de las antiguas, muchas de las cuales reconocen sus propias claudicaciones, y tratan de rehacerse desde la autocrítica. Además, al autoritarismo estatal se ha sumado otro que no deja mucho margen de maniobra y que invita a no cejar en el esfuerzo articulador de la indefensa sociedad civil.

En la Lima de 1993, bajo la dictadura de Fujimori y el terrorismo de Sendero Luminoso, con la creciente pobreza y la dificultad de combatirla desde una sociedad fragmentada, adquiere visibilidad una nueva propuesta cívica. Es una propuesta de rechazo a ambas formas de autoritarismo y a sus secuelas, por parte de los sectores sociales que han sido sus principales depositarios y víctimas. Es además una propuesta de reconstrucción del sistema político para el desarrollo integral, que aparece en las cuatro zonas estudiadas. Portavoces de los comedores populares, de la Central de Trabajadores Autónomos del Perú y de la Coordinadora Vecinal del Cono Norte resumen bien los contenidos de la propuesta.

Hablan las primeras: "Dicen (se refieren a Sendero Luminoso) que nosotras colaboramos con el gobierno, lo único que hacemos es impedir que la gente se muera de hambre ¿Quiénes son ellos para matar?". Dicen los segundos "Estamos rodeados por el gobierno y por SL, echamos pa adelante, si sabemos que vamos a morir mañana ¿por qué nos vamos a ocultar hoy día?... hay que dar el cuerpo, con dos días de paro armado la gente ha participado en nuestra conferencia, creíamos que no iba a venir nadie, con cuatro compañeros que los quemaron ahí en los buses... pero ahí estuvo la gente... estudiando su problema para darle una respuesta concreta al gobierno". Varios testimonios más se resumían así: "El terrorismo es juvenil pero solo puede contrarrestarse con mejora de la calidad de vida y con organización social, hay que integrar a los jóvenes en la sociedad, por la educación y el trabajo, hay que abrir paso a su participación, y al recambio en las organizaciones populares". Declaran los terceros: "La democracia no tiene que ser una

(7) El reformismo militar de Juan Velasco Alvarado se extiende desde la toma del poder, por medio del golpe militar que desplaza a Fernando Belaúnde Terry en 1968, hasta su caída en 1974. El gobierno del Perú sigue bajo mando militar hasta las elecciones de 1980. Accede nuevamente Belaúnde Terry con Acción Popular hasta 1985. Le sucede el aprismo de Alan García y en 1990 gana las elecciones el actual presidente Fujimori, quien meses más tarde da un golpe de estado a su propio gobierno constitucional. entelequia sino que tiene que volver a los gobiernos locales. Es ahí donde hay una mayor posibilidad de reconstruir el sistema político porque puede haber ligazón política con la gente, donde puedes dar tu propia opinión, donde puede haber una política que se dirija al bienestar de la gente, no es casualidad que Fujimori apunta ahí, es el último reducto de la democracia del país".

La respuesta popular se consolida en torno a las prácticas de aquellos grupos que combinan estratégicamente (por tanto con flexibilidad y diversidad) las normas, valores y creencias solidarias compartidas por tradición, en torno a la comunidad primitiva, con los requerimientos modernos de las identidades múltiples, afirmadas en torno a la emancipación de la mujer, al reemplazo generacional, a la discriminación étnica y a la desigualdad social. También se pretende abolir el liderazgo tradicional que se detenta por adscripción con el moderno que se adquiere por elección.

Un elemento esencial a la normatividad social emergente es, la reversión del clientelismo. Un elemento esencial a las nuevas formas de participación popular es la disposición a consolidar los movimientos de base mediante la formación de sus líderes en las tareas de dirección organizativa (con criterios de democracia y eficacia), de coordinación interinstitucional y de representación política.

\section{LA REVERSIÓN DEL CLIENTELISMO.}

El clientelismo político, como cara amable del liderazgo autoritario atrapa al pueblo llano en los barrios con donaciones o simples promesas, a través de las organizaciones que hacen de correa de transmisión y filtro de los favores del gobierno.

La indignidad de la relación, como cara amarga del clientelismo, lo hace inadmisible cuando las promesas se incumplen, y el engaño se vocea. La conciencia popular se va modificando y aparecen nuevas estrategias de respuesta, que buscan el talón de Aquiles de la práctica clientelar. Y éste, según nuestros interlocutores se encuentra más fácilmente en los períodos electorales.

El acercamiento del dirigente político al vecino se realiza en campaña electoral, para intercambiar promesas electorales por votos. La respuesta vecinal da un giro al intercambio, para condicionar su voto en una doble estrategia de fidelidad a la vecindad.

En primer lugar, con la exigencia de atención a las demandas antes de la votación. En segundo lugar, poniendo un filtro al voto. La palabra dada al candidato, no es vinculante sino cuando la valoración popular lo aconseja. En caso contrario, la defensa del interés común obliga a la infidelidad hacia el aspirante:

"Somos bien democráticos pero no somos políticos ninguno. Nosotros decimos, bueno, si ellos vienen a ofrecerse, ese momento hay que aprovecharlo, porque ya después quien sabe, luego el voto es secreto y nosotros somos independientes". (Grupo de Mujeres de El Agustino). 
En este ámbito, el de la vecindad, toca a las bases sociales juzgar la solidez de la voluntad política de un candidato, no sólo en función de sus ideas sino de sus posibilidades de sortear los obstáculos que desde su partido y desde otros grupos de interés se le van a colocar. Tienen que ponderar, también, la voluntad política del partido, conscientes de la jerarquización existente a su interior y obtener el máximo de ganancias en el corto plazo de la campaña electoral. Este ejercicio resolutivo es considerado como parte del quehacer democrático "directo", que debe ser ejercido por encima de todo partidismo o claudicación al clientelismo "la falsa representación política".

El pueblo votante es aquí el actor social que ha encontrado una estrategia de conducta reversa. La falsedad del político justifica el rapto de la moral (8) para practicar una conducta de la vida profundamente ligada al orden vital comunitario (siguiendo a Weber), allí donde se construyen las normas, valores y creencias sociales.

Tal como están las cosas, las organizaciones políticas no alcanzarán la credibilidad deseada sólo mediante la adquisición de compromisos coyunturales. Para lograrla tienen que volver a ser capaces de representar los intereses populares. en condiciones adversas. recuperando el espacio político que hoy les niega una dictadura que aprovecha la crisis de las instituciones políticas democráticas para justificar su disolución.

\section{LA TRANSFORMACIÓN DEL TEJIDO SOCIAL URBANO EN TIEMPOS DE EMERGENCIA SOCIAL.}

¿Cómo afecta la crisis económica a la transformación del tejido social urbano?. Por lo pronto, provoca la aparición de nuevas organizaciones de resistencia a la crisis, que ocupan el espacio vecinal junto a las tradicionales juntas de vecinos. Las más desarrolladas son aquellas que combinan estrategias de sobreviviencia, mediante la puesta en común de los recursos colectivos, lo que logran y expectativas de trascender los contenidos asistenciales, mediante la producción de bienes y servicios y la creación de puestos laborales cualificados para el desarrollo de estas funciones productivas, lo que está por lograr. Aparecen también organizaciones ligadas al trabajo informal, a la microempresa y a la venta ambulante.

Las organizaciones de sobrevivencia que adquieren mayor densidad y destreza organizativa son los comedores autogestionarios (9), cuyo protagonismo pertenece a las mujeres y cuya fortaleza depende de su capacidad de trascender el micromundo de la función alimentaria, tanto al interior del ámbito barrial, como fuera de él.

Para incorporarse a las tareas de resolución de los problemas locales tienen que trabajar en coordinación con las

(8) Expresión acuñada por Salvador Giner (1987b).

(9) Conviene recordar que existen varios tipos de organizaciones alimentarias, unas de ellas surgidas de los propios pobladores, a iniciativa vecinal o parroquial, y otras de programas de gobierno de varias legislaturas. Es abundante la bibliografía que estudia su historia y dinámica. Ver, por ejemplo, Delpina (1991). otras instituciones y en interacción con el poder local. Para ocuparse de problemas suprabarriales deben desarrollar instancias organizativas que liguen la acción asistencial barrial y distrital con la metropolitana y con la nacional y hacer respetar su competencia para participar en el diseño de las políticas sociales del estado.

Lo primero es posible allí donde existe un proyecto municipal impulsor de la participación popular en el desarrollo local. Lo segundo, va fermentando allí donde existe un proyecto institucional de apoyo a la formación de líderes y a la profesionalización de la acción colectiva.

Una organización de comedores empeñada en hacerse un lugar en ambos escenarios trabaja en El Agustino.

\section{LA PROYECCIÓN LOCAL DE LOS COMEDORES EN EL AGUSTINO}

En el Agustino hay un proyecto de desarrollo integral que surge a propuesta del alcalde de Izquierda Unida en 1987 y que en el momento de hacer la investigación se descentraliza en ocho MIADES (microáreas de desarrollo). Hay una voluntad política inicial de cogestión con todo el tejido asociativo de cada una de las MIADES, formado por "cooperativas, organizaciones vecinales, de comedores, de clubes de madres, del vaso de leche, de talleristas, de vendedores ambulantes, de pequeños artesanos, de padres de familia (AFAPAS), de maestros (SUTEP) y parroquias. El objetivo es debatir los problemas y decidir su solución sobre un fondo de desarrollo comunal "el pueblo decide, la alcaldía ejecuta y el pueblo fiscaliza el gasto y la obra hecha", según el alcalde.

Pero surgen discrepancias entre la alcaldía y las organizaciones, por lo que la primera califica de falta de reconocimiento del liderazgo político del ayuntamiento y éstas juzgan de hegemonismo de la autoridad municipal: "Quieren que la presidencia de las reuniones con cada MIADES sea rotatoria .. incluso hay ONGS (Organizaciones no gubernamentales) que llegaron a plantear que la municipalidad es una instancia más, igual que un pueblo... no reconocen la autoridad del gobierno local... quieren reemplazar a la municipalidad". (Alcalde. )

Desde la Coordinadora Metropolitana de Organizaciones Vecinales la interpretación es distinta: "La propuesta en El Agustino era construir un espacio de concertación entre la organización popular, el municipio, la iglesia, la comisaría, es decir todas las fuerzas vivas del distrito que se sientan en igualdad de condiciones para definir prioridades, para levantar planes de emergencia y para implementarlos... Quien conduce actualmente el municipio limitó la concepción a hegemonía y control".

Y desde el barrio, las dirigentes de comedores autogestionarios plantean también su visión, que es la de quienes han ganado, con esfuerzo, un espacio social para participar en la puesta en común de los problemas de la comunidad, y a las dificultades iniciales de aceptación de su presencia por parte de las organizaciones vecinales (la fricción de género 
es aquí parte importante de la experiencia relatada), suman ahora su percepción de dirigismo-clientelismo municipal: "Hay MIADES que sí tienen esa relación con el municipio y apoyo pero hay otras que no... en vez de apoyar a la junta directiva en forma conjunta ha formado otra junta con otro grupo que estaba con él, que lo ha apoyado en el momento de las elecciones.. , ahora nos sentamos en la mesa que el quería dirigir... nosotros luchamos para que sea rotativo, no queremos que el municipio sea el papá en una palabra del distrito y que nos esté siempre mandando, venimos aprendiendo, tantas cosas que nosotros no sabemos"

En otro momento y avanzando en la conciencia de representación desvelan que el Alcalde llegó a cerrarles la puerta del local de reunión municipal que sólo se abría a los grupos afines. La unidad de gestión de la MIADES empezó a reunirse fuera del local para acabar entrando al local "porque es de todos" y además "somos dirigentes porque la gente ha depositado su confianza en uno, porque levantas propuestas, porque reclamas, eres un refuerzo para ellos".

Cuando las dirigentes hablan así ya han logrado ser aceptadas por las otras organizaciones pero sus dificultades iniciales son claramente descritas como de un doble carácter:

-De aceptación masculina de las mujeres en lo que consideran su propio espacio y funcionalidad social.

-De cesión por parte de las organizaciones tradicionales de espacio público para nuevas organizaciones con capacidad de articularse en torno a las demandas que hasta ahora constituían parte del espacio doméstico, y en consecuencia de aceptación de estas organizaciones en el debate público y en la coordinación de estrategias de acción.

Gracias a ello "El Agustino es el primer distrito del Perú que ha logrado, sentar todas esas organizaciones en una mesa, a planificar qué hacemos ante la crisis" y ahora "las mujeres ocupamos un campo... tenemos un sitial y no sólo en El Agustino, incluso a nivel nacional ya tenemos una Federación de comedores... hemos pedido apoyo a entidades, asesoramiento, así venimos trabajando". (Dirigentes de Comedores de El Agustino).

La experiencia que nace como servicio se convierte en espacio de promoción de la mujer y en espacio de debate ciudadano sobre la reconstrucción de la representación política, sobre los limites entre la democracia directa y la representativa y sobre el clientelismo.

\section{LA FORMACIÓN DE DIRIGENTES DE COMEDORES PARA TAREAS DE REPRESENTACIÓN}

Una constante en todos los discursos analizados es la referencia al apoyo de la Iglesia Católica en la promoción de la actividad barrial. A través de sus instituciones (las parroquias, Cáritas, Fe y Alegría), ha potenciado la formación y consolidación de estas organizaciones en el ámbito municipal. El Agustino es un ejemplo.
Una iniciativa nacional para institucionalizar estas organizaciones es la que toma la Comisión Episcopal de Acción Social. La portavoz de la organización no gubernamental FOVIDA (10) la expresa así:

"En 1986, la Comisión Episcopal convoca un primer encuentro nacional de comedores, al que asisten 1, 200 delegadas de todo el Perú y en el que reflexionan sobre dos aspectos importantes de la organización: sus logros en la implementación de políticas sociales abandonadas por el Estado, en el campo de la alimentación y la salud y su irreemplazable aporte a la comunidad. Tal reflexión les conduce al reconocimiento de su importancia para la integración social y de su legitimidad como interlocutores válidos con el Estado".

Su primera acción hacia el estado fue la elaboración y envío al gobierno de Alan García de un documento que contiene varios puntos, en los que se constata la repercusión de la situación económica del país en las familias y vecindades de los pueblos jóvenes y asentamientos humanos y la marginación de los comedores autogestionarios frente a los gubernamentales. Se exige atención a las organizaciones populares equiparable a la recibida por los comedores del gobierno, promoción de las cunas infantiles, PRONOID y talleres ocupacionales para la mujer.

El documento no obtuvo respuesta de Alan García, pero la organización de comedores se reafirma en una propuesta popular de interacción con el Estado radicalmente opuesta a las prácticas populistas habituales Una representación de la ciudadanía expresa sus demandas al Estado y reclama el reconocimiento de su entidad como instancia organizativa de competencia nacional.

\section{HACIA EL FUTURO.}

Vistas estas experiencias desde diciembre de 1992, no parecen sino parte de la historia de un movimiento truncado, o congelado en sus expectativas. El reclamo sigue en pié pero el poder de convocatoria y la dinámica interactiva han disminuido por una doble razón. La negativa del poder político a negociar con la organización de comedores dentro de los límites ciudadanistas contemplados en la propuesta. El repliegue de actividad causado por la condena a muerte que pende implacable sobre los dirigentes sociales empeñados en construir la ciudadanía.

El discurso del poder político, en cuanto puede tejerse a partir de la visión que sobre las organizaciones populares nos transmite la asesoría del Ministerio de la Presidencia no se plasma en una política de fomento a la participación, a juzgar por la opinión que de la política social de FONCODE (Fondo de Cooperación al Desarrollo) tienen las ONGs (organizaciones no gubernamentales) y las organizaciones populares y que se resume en "invisibilidad" (11).

(10) Están presentes Cimbote, Ilo, Arequipa y Huancayo, además de Lima.

(11) Se dispone de una relación amplia de criterios y planes de acción de FONCODE que no pueden analizarse aquí. De ahí que se anote sólo la percepción popular. 
Por el contrario, la amenaza terrorista sí se plasma en asesinatos y matanzas.

Volviendo al discurso del poder político. Hay un reconocimiento claro de la evolución de la expectativa de las bases sociales hacia el Estado y de la legitimidad social con la que los comedores la recogen. El asesor del Ministerio de la Presidencia explica que la organización de comedores populares adquiere hoy más relevancia para la administración estatal de los recursos sociales que cualquier otra institución tradicional de reivindicación popular, tanto por su capacidad aglutinadora como por el giro de las demandas, por su continente pacificador y por su, al menos inicial, apoliticismo. ¿Por qué, entonces, un análisis que podría suscribir gran parte del movimiento social urbano no se traduce en la creación de un espacio amplio de interlocución social?

Parece claro que la concepción autoritaria de la gestión política facilita la puesta en marcha de políticas de ajuste y de defensa del orden público. El gobierno de Fujimori puede hoy apoyarse en el escepticismo popular hacia las instituciones políticas y hacia las organizaciones sociales que más compromisos políticos han adquirido en el pasado para descalificarlas, apelando, en nombre del pueblo, a la solidaridad étnica de la tradición indigenista, cuyos componentes suscribe simbólicamente. No en vano el mismo Fujimori pertenece a una de las etnias "no blancas" del espectro social peruano.

Desde el Estado se lanza hoy un mensaje más "basista" que desde cualquiera de las instancias religiosas, políticas y sociales, pero la fidelidad popular a cualquier causa, se ha visto, pasa por la evaluación de resultados, en lectura pragmática y supersensible al clientelismo y al engaño. La población aprueba medidas represoras de la violencia subversiva pero rechaza su aplicación indiscriminada a los sectores más desvalidos de la sociedad civil. Reconoce la existencia de ayudas sociales pero las valora como escuálidas. Las organizaciones no gubernamentales ven disminuido su margen de maniobra y las organizaciones populares saben que "el estado no recibe y no quiere negociar" (Coordinadora Metropolitana de Organizaciones Vecinales). Llenar las expectativas populares de desarrollo integral de la sociedad peruana por medio de la participación en la elaboración de planes de desarrollo y en la gestión de los recursos, es un reto también para el Estado. El gobierno, como institución política emblemática tiene, al igual que los partidos y las organizaciones vecinales y laborales, la necesidad de demostrar su utilidad para aminorar las desigualdades sociales y por tanto su legitimidad para arbitrar medidas de salida efectiva de la crisis.

Después del referendum popular para la reforma de la Constitución, que le da más poder de actuar, Fujimori sabe que la contestación a su política aumenta conforme se reducen los votantes que le apoyan.

Es indudable la capacidad de resistencia de las poblaciones en momentos de crisis y su habilidad para echar mano de las viejas instituciones de organización comunitaria indígena a fin de arbitrar con rapidez acciones de so- brevivencia. Pero no lo es menos que la tradición comunitaria, aquella que hoy se erige en la seña de identidad más ampliamente reconocida, se conforma con elementos diversos y cambiantes, con recuerdos y olvidos que no son sino flujos de erosión, e invención, de la memoria común. La experiencia de participación ciudadana reciente es uno de los recuerdos que adquiere mayor vivacidad, a medida que las organizaciones populares van siendo capaces de transformar las necesidades e intereses diversos en iniciativas de acción colectiva. El clamor unánime por la participación, el "queremos gestionar, la educación, la cultura, la producción de trabajo, no reivindicar" parece ser una de las afirmaciones que hoy produce menos desacuerdos y que se dota de más significados. El secreto esta en saber integrar las herencias del pasado con las más radicales experimentaciones del presente.

\section{BIBLIOGRAFIA}

BALLON, E, Editor (1991): Movimientos sociales y democracia. La fundación de un nuevo orden, DESCO, Lima.

ECKSTEIN, S. Ed. (1989) Power and Popular Protest. Latin American Social Movements. University of California Press, Berkeley.

GELLNER, E (i989): Cultura, Identidad y Política, Gedisa, Barcelona.

GINER, S (1987a): El destino de la libertad, Espasa-Calpe, Madrid.

GINER, S (1987b): Ensayos Civiles, Península, Barcelona.

GLAZER, N. Y MOYNIHAN, D. EDITORES (1975): Ethnicity, Harvard University Press, Cambridge.

GONZALEZ CASANOVA, P. y ROITMAN ROSENMANN, M. COORD. (1992): La democracia en América Latina, Editorial Complutense, Madrid.

LEHMANN, D ( 1990) : Democracy and Development in Latin América. Polity Press, Cambridge.

López Jiménez, M. A. (1993): Memoria y Nacionalismo, Seminario de la Paz, Zaragoza y CIP, Madrid.

López Jiménez, M. A. (1987): Los Bienatados. Jóvenes en Zaragoza, 2 Volúmenes Institución Fernando el Católico del CSIC, Zaragoza.

NELSON FERREIRA, C. (1981): Movimientos Urbanos No Rio de Janeiro, Zahar.

OLIVERA, Luis (1994): "Lima y su organización urbano popular", en Las ciudades hablan. Nueva Sociedad, Caracas (en prensa).

PASARA, L. DELPINA, N. VALDEAVELLANO R. Y Zarzar A. (1991): La otra cara de la luna. Nuevos Actores Sociales en el Perú, CEDYS, Buenos Aires.

PEREZ DIAZ, V (1987): El retorno de la sociedad civil, Instituto de Estudios Económicos, Madrid.

QUEDENA, Enrique y otros. (1988) Derecho, promoción social y sectores populares urbanos, Lima, Lima

RIOFRIO, Gustavo. (1991) Producir la ciudad (popular) de los '90. Entre el mercado y el Estado. Lima: DESCO

RODRIGUEZ VILLASANTE, T (1991): Movimiento ciudadano e iniciativas populares, Ediciones HOAC No 16 , Madrid. 
RODRIGUEZ VILLASANTE, T. (1984): Comunidades Locales. IEA, Madrid.

SANCHEZ PARGA, J y otros (1992): Identidades y sociedad, Centro de Estudios Latinoamericanos/PUCE, Ecuador

SOCIAL MOVEMENTS, Monográfico en el Journal IN-
TERNATIONAL SOCIOLOGY VOLUME 5, NUMBER 2, JUNE 1990, CARDIFF.

TOURAINE, Alain. (1989) América Latina: política y sociedad. España: ESPASACALPE

\section{RESUMEN}

Con base en una investigación empírica realizada con técnicas cualitativas, se analiza la formación de organizaciones y acción colectiva en distintos tipos de estratos sociales en la ciudad de Lima. La vivencia cotidiana de la pobreza, que también incide en la crisis de identidad masculina y en la autoestima femenina; la relación de la cultura tradicional comunitaria de origen indígena con la atomización de la sociedad urbana; y la vinculación de las organizaciones de la sociedad civil con el sistema político en el contexto histórico peruano, son los factores destacados para interpretar la situación actual y las potencialidades de la acción colectiva en Lima.

ABSTRACT
Starting from an empirical research using qualitative methods, this article analyzes the formation of
organizations and collective actions in different social stratums in the city of Lima. The dairy
poverty which also affects the crisis of the masculine identity and female self-respect; the
relationship between the traditional communitarian culture of indigenour origin and the atomization
of the urban society; and the linkage between the organizations of the civil society and the political
system in the Peruvian historical context. All of them are the most important factors in order to
interpret the present and the potentialities of the collectiva action in Lima.

